\title{
Estudio comparativo cineantropométrico de karatekas pertenecientes a la selección universitaria Inca Garcilaso de la Vega y a la Selección \\ Peruana. Lima. Mayo 2010
}

\author{
Jamee Guerra, Rosa Oriondo \\ Universidad Inca Garcilaso de la Vega y Federación Peruana de Karate
}

Objetivos: Comparar las características cineantropométricas de la selección universitaria Inca Garcilaso de la Vega y Peruana de karate.

Diseño: Descriptivo, transversal.

Institución: Universidad Inca Garcilaso de la Vega y Federación Peruana de Karate.

Participantes: 34 karatekas, ambos sexos, entre 16 y 30 años, pertenecientes a la selección universitaria Inca Garcilaso de la Vega y a la selección Peruana.

Intervenciones: Las mediciones antropométricas (pliegues, perímetros, segmentos corporales y diámetros óseos) fueron realizadas según el protocolo ISAK. Se analizó 20 variables antropométricas.

Principales medidas de resultados: Composición corporal y somatotipo.

Resultados: En las selecciones nacional y universitaria respectivamente, el porcentaje de masa adiposa fue en promedio $25 \%$ y $27 \%$ en varones y $33 \%$ y $35 \%$ en mujeres; el porcentaje de masa muscular fue $48 \%$ y $47 \%$ en varones, $43 \%$ y $40 \%$ en mujeres. Los somatotipos encontrados en varones fueron el mesomorfo balanceado y mesoendomórfico para la selección peruana y universitaria, respectivamente; en las mujeres fue endomesomórfico en ambas selecciones. Solo existió diferencia significativa en el somatotipo de varones de diferentes selecciones $(p<0,01)$.

Conclusiones: La composición corporal y el somatotipo de la selección universitaria no fueron óptimos. La selección nacional presentó valores más cercanos a los estándares internacionales.

Palabras clave: Cineantropometría, composición corporal, somatotipo, karate.

\section{Nivel de consumo diario de frutas y verduras en escolares con sobrepeso y obesidad del primer y segundo grado de primaria de la Institución Educativa Particular San Andrés. Lima. Mayo 2011}

Katherine Alfaro

\author{
Institución Educativa Particular San Andrés
}

Objetivos: Determinar el nivel de consumo diario de frutas y verduras en escolares con sobrepeso y obesidad de primer y segundo grado de nivel primario de la IEP San Andrés.

Diseño: Estudio descriptivo, transversal, observacional y prospectivo.

Institución: Institución Educativa Particular San Andrés.

Participantes: Veintisiete escolares con sobrepeso y 33 con obesidad, de primer y segundo grado de nivel primaria.

Intervenciones: Aplicación de formato de frecuencia de consumo de frutas y verduras, previamente validada con ayuda de un laminario de frutas y verduras.

Principales medidas de resultados: Consumo de frutas y verduras en gramos/día (g/d) y por tipo.

Resultados: El consumo diario de frutas y verduras de la población, según el estado nutricional, fue en promedio de $340+70$ y $286+116 \mathrm{~g} / \mathrm{d}$, para los escolares con sobrepeso y obesidad, respectivamente. El $75 \%$ de los encuestados consumió menos de $400 \mathrm{~g}$ de frutas y verduras/d. Las frutas más consumidas fueron la mandarina, el plátano y la manzana; en caso de las verduras fueron el tomate, pepinillo y la coliflor.

Conclusiones: El consumo de frutas y verduras diariamente fue inadecuado en $75 \%$ de la población estudiada, mientras que solo en $25 \%$ fue adecuado.

Palabras clave: Frutas, verduras, sobrepeso, obesidad. 